\title{
Crystallization of polylactide-based green composites filled with oil-rich waste fillers
}

\author{
Olga Mysiukiewicz ${ }^{1}\left[\right.$ Mateusz Barczewski ${ }^{1}$
}

Received: 2 June 2020 / Accepted: 31 October 2020 / Published online: 18 November 2020

(c) The Author(s) 2020

\begin{abstract}
Polylactide is a highly demanded biopolymer, whose industrial application constantly increases. Its disadvantages such as brittleness and slow crystallization rate can be overcome by application of different additives. Because of environmental issues, using natural waste fillers as modifying agents for polylactide is especially interesting. In this study linseed cake, a byproduct of oil extraction from linseed, characterized by oil content of 0.9-39.8 wt.\%, was added to polylactide to influence its crystallization behavior. The formation of the crystalline phase was studied by differential scanning calorimetry in isothermal and non-isothermal conditions and analyzed according to methods by Jeziorny, Ozawa, Mo and Avrami. The samples' microstructures were observed using polarized light microscopy. The crystallization rate and Avrami exponent of samples crystallized in different conditions were evaluated. It was found that addition of $10 \mathrm{wt} . \%$ of linseed cake containing at least $17.7 \mathrm{wt} . \%$ oil notably changes the crystallization of polylactide, increasing its crystallinity and promoting the growth of crystallites.
\end{abstract}

Keywords Polylactide $\cdot$ Linseed cake $\cdot$ Composite $\cdot$ Waste filler $\cdot$ Crystallization kinetics

\section{Introduction}

Since 1990 s, when a need to find a sustainable alternative to conventional polymeric materials became evident, polylactide or poly(lactic acid) (PLA) is gaining more and more popularity. This so-called biopolymer, which can be synthesized from the lactic acid resulting from fermentation of starch [1-4] and can undergo biodegradation in industrial conditions $[1,4-7]$ is successfully applied as a 3D-printing filament and as a material for production of packages, disposable goods, biomedical devices, automotive applications and fiber [1, 2, 8-10]. Environmental friendliness is not the sole feature which makes polylactide so popular these days. PLA is an aliphatic polyester whose mechanical properties are similar to those of poly(ethylene terephthalate) or polypropylene [11]. It is relatively strong (tensile strength around 45-65 MPa [2]), rigid (tensile modulus $>3 \mathrm{GPa}[2]$ ) and easy to process using conventional technologies [1]. Polylactide is a semi-crystalline

Olga Mysiukiewicz

olga.mysiukiewicz@put.poznan.pl

1 Institute of Material Technology, Poznan University of Technology, Piotrowo 3, 61-138 Poznan, Poland polymer, whose crystalline form can be characterized with good mechanical properties and thermal stability (heat deflection temperature exceeding $90^{\circ} \mathrm{C}$ [12]). Unfortunately, due to lack of the flexible methylene segment in its backbone, the crystallization rate of PLA is very slow [3, 13]. A profound knowledge of polylactide crystallization behavior is crucial to improve its properties and make the processing more efficient [14]. Thanks to the relentless efforts of the researchers and dozens of studies, there are multiple procedures which can be applied to overcome the disadvantages caused by amorphous structure of PLA. One of them is modification of PLA by nucleating agents (NAs), which serve as crystallization seeds and increase the rate of crystallization. Different substances, including aromatic sulfonate derivatives [12, 15], talc [16, 17], montmorillonite $[18,19]$ and other silicates [20], calcium carbonate [14], carbon nanotubes [19, 21] or graphene [22] were shown as effective NAs for PLA and some of them are successfully applied in industrial applications. Apart from NAs, plasticizers are also a common additive for PLA. Even though their primary role is reducing brittleness and increasing impact strength, they also influence the crystallization behavior of this polymer, especially when they are applied together with a nucleating agent. 
For example, addition of triphenyl phosphate, a plasticizer commonly used for poly(vinyl chloride) increased crystallization rate of polylactide [23]. Plasticizers such as poly(ethylene glycol) and acetyl triethyl citrate combined with talc caused an increase in PLA's crystallinity [24]. Natural jojoba oil also increased crystallization rate of polylactide, but did not influence the kinetic energy of crystallization [25]. Properties of polylactide can also be changed by producing composites based on this material. The resulting properties of a PLA-based composites depend on multiple factors including the chemical composition of the filler, its shape and size, preparation procedure and the amount of the additive. Among many other features, the crystallization behavior can also be altered by addition of certain fillers to polylactide matrix. This effect is especially prominent in the case of nanocomposites, as the nanoparticles of silica, montmorillonite or calcium carbonate were shown to act as nucleating agents [19], however various micrometric fillers such as ground eggshells [26], babassu mesocarp [13] or basalt powder [27] also showed an advantageous influence on PLA crystallinity.

As PLA is considered a "green" polymer, it is important to not to "spoil" its environmental friendliness by application of unsustainable modifying agents. To achieve this goal, many natural- or plant-based substances were tested for its influence on polylactide properties. For example, epoxidized or maleinized natural oils were shown as effective plasticizers for PLA [28-31]. Hazelnut skins and cocoa waste were successfully used for production of plasticizers, antioxidants and reinforcements for polylactide [32]. Natural extracts from cocoa, coffee and cinnamon have an anti-aging effect on PLA, but their application does not limit the biodegradation of the polymer [5]. Numerous natural and waste fillers can improve mechanical properties of the PLA-based composites [33-36]

One of the promising environmentally friendly additives for polylactide is linseed cake (LC). It is a waste product of oil extraction from linseed (Linum usitatissimum L.), which does not have a large-scale industrial application [37]. As our previous research has shown, because of simultaneous presence of rigid lignocellulosic particles and natural linseed oil, LC can be successfully used as a filler for PLA-based composites. Its addition reduces brittleness, changes the ageing behavior and crystallization of polylactide [38-40]. Even though notable changes such as the disappearance of cold crystallization and an increase of crystallinity degree was observed in PLA-based composites filled with linseed cake, the phenomena behind these changes were not identified.

The aim of this paper is an analysis of the influence of linseed cake on melt crystallization behavior of PLA performed in both non-isothermal and isothermal conditions according to the methods by Jeziorny, Ozawa, Mo and Avrami. This work is intended to provide a better insight into the crystallization kinetics of biopolyester filled with naturalbased waste fillers as well as to obtain useful, practical information to optimize the production of PLA-based composites.

\section{Materials and methods}

\section{Materials}

A multipurpose injection molding polylactide grade Ingeo $2500 \mathrm{HP}$ by Natureworks characterized by mass flow index (MFI) of $8 \mathrm{~g} / 10 \mathrm{~min}\left(210^{\circ} \mathrm{C}, 2.16 \mathrm{~kg}\right)$ and d-isomer content of $<0.5 \%$ was used. Linseed cake was purchased from a local Polish supplier as an oil production waste. Its chemical composition is given in Table 1 . In order to analyze the influence of natural oil content in the filler on the crystallization of the PLA-based composites, LC was subjected to partial defatting in acetone, according to the procedure described in our study [38]. As a result, 5 grades of linseed cake with various oil content were obtained. The oil content established by Soxhlet extraction in petroleum ether (total extraction time of $150 \mathrm{~min}$ ) using a Büchi Universal Extraction System B-811 was equal to $0.9 \%, 4.6 \%, 17.7 \%, 30.4 \%$ and $39.8 \%$, respectively. The linseed cake particles were also screened using a Fritsch Analysette Pro 3 sieve shaker using a $630 \mu \mathrm{m}$ mesh.

\section{Sample preparation}

The composite samples were prepared by mixing in molten state method. First, PLA pellets and $10 \mathrm{wt} \%$ of chosen linseed cake powder were preliminarily mixed and dried at $70^{\circ} \mathrm{C}$ overnight in a Memmert ULE500 cabinet drier. This step was necessary to minimize the moisture content in the hydrophilic natural filler, which could cause a hydrolytic degradation of polylactide during processing [41]. Then, the polymer and the filler were mixed using a ZAMAK EH-16.2 D co-rotating twin screw extruder at maximum processing temperature of $190^{\circ} \mathrm{C}$ (set at the die) and screws speed of $100 \mathrm{rpm}$. The extrudates were cooled in the forced

Table 1 Chemical composition of linseed cake containing $30.4 \mathrm{wt} \%$ of oil

\begin{tabular}{ll}
\hline Component & $\begin{array}{l}\text { Amount as a } \\
\text { wt\% of dry } \\
\text { mass }\end{array}$ \\
\hline Oil & 30.40 \\
Cellulose & 11.53 \\
Lignin & 7.33 \\
Hemicellulose & 6.23 \\
Mineral matter & 4.53 \\
Proteins, saccharides, and other components & 39.98 \\
\hline
\end{tabular}


air flow, pelletized, and dried as before. The samples were prepared using the injection molding method using a Battenfeld PLUS-35 machine with the following parameters: $T_{\text {injection }}=210^{\circ} \mathrm{C}, T_{\text {mold }}=50^{\circ} \mathrm{C}, p_{\text {injection }}=72 \mathrm{MPa}$, $v_{\text {injection }}=75 \mathrm{~mm} / \mathrm{min}$. The unfilled PLA was processed in the same way as the composites.

The samples were named according to the used linseed cake grade, that is LC0.9, LC4.6, LC17.7, LC30.4 and LC39.8. The unfilled sample was marked as PLA.

\section{Experimental}

\section{Differential Scanning Calorimetry (DSC)}

\section{Non-isothermal crystallization}

The DSC crystallization studies of the PLA and its composites was evaluated by differential scanning calorimetry (DSC) technique using a Netzsch DSC 204 F1 apparatus. Samples of $5 \pm 0.2 \mathrm{mg}$ were placed in aluminum crucibles with pierced lids and examined in a Nitrogen atmosphere. During non-isothermal crystallization investigations, the specimens were firstly heated at a rate of $30^{\circ} \mathrm{C} / \mathrm{min}$ from $20^{\circ} \mathrm{C}$ to $210^{\circ} \mathrm{C}$ and held at this temperature for $5 \mathrm{~min}$ in order to ensure, that the material was completely molten and its thermal history was erased. Then, it was cooled back to $20^{\circ} \mathrm{C}$ at a rate of $2.5,5,7.5^{\circ}$ and $10 \mathrm{C} / \mathrm{min}$. After stabilizing the sample at $20^{\circ} \mathrm{C}$ for $5 \mathrm{~min}$, it was heated once again to $210^{\circ} \mathrm{C}$ at a rate of $10^{\circ} \mathrm{C}$. The crystallinity degree $X_{c r}$ was calculated based on the melting and cold crystallization enthalpy obtained from the second heating cycle according to the formula (1):

$X_{c r}=\frac{\Delta H_{m}-\Delta H_{c c}}{(1-\varphi) \Delta H_{100 \% P L A}} \cdot 100 \%$

where: $\Delta H_{m}$-melting enthalpy of the sample, $\Delta H_{c c}$-cold crystallization enthalpy of the sample, $\Delta H_{100 \% P L A}$-melting enthalpy of a $100 \%$ crystalline PLA, $\Delta H_{100 \% P L A}=93 \mathrm{~J} / \mathrm{g}$ [42], $\varphi$-filler content, $\varphi=0.1$ for the composite samples with $10 \mathrm{wt} \%$ of the filler and $\varphi=0$ for the pure PLA.

Based on the obtained data, the values of crystallization rate $k_{J}$ and the exponent $n_{J}$ were calculated using a method proposed by Jeziorny [43]. According to Avrami, crystallization of polymers proceeds according to the relationship (2)

$1-X(t)=\exp \left[-k t^{n}\right]$

where: $X(t)$-the relative crystallinity (the degree of conversion), $t$ - time, $k$ - rate constant, $n$ - Avrami exponent.

To determine the $k$ and $n$, formula (2) can be written in the following form (3) [44]: $\log [-\ln (1-X(t))]=n \log t+\log k$

The values of the relative crystallinity $X(t)$ obtained at a time $t$ during the DSC experiment can be plotted as $\log [-\ln (1-X(t))]$ vs. $\log (t)$. The calculations were performed for the conversion degree in the range of $3 \%-20 \%$, to exclude the secondary crystallization phenomena which may take place afterwards [44, 45]. When a straight line can be fitted to the plot, the value of Avrami exponent can be read from its slope and $\log k$ is the intercept.

Taking into consideration that the Avrami equation is true for the reactions taking place in at a constant temperature, Jeziorny proposed the corrected form of the crystallization rate $k_{J}$ [43], as shown in formula (4):

$\log k_{J}=\frac{\log k}{\beta}$

where $\beta=\mathrm{d} T / \mathrm{d} t$ - cooling rate.

Taken into consideration that crystallization of polymers is a complex process composed of many simultaneous phenomena, such as crystallite nucleation and growth, other models were also used, to fully understand the crystallization of PLA.

According to Ozawa, non-isothermal crystallization can be divided into infinitesimal isothermal steps and hence described as in formula (5) [46]:

$X(T)=1-\exp \left(-K(T) / \beta^{m}\right)$

where: $X(T)$-cooling function of non-isothermal crystallization, $m-$ Ozawa exponent. The value of $\mathrm{m}$ can be obtained from plots of $\ln [-\ln (1-X(T))]$ vs $\ln (\beta)$ as the slope of the curve according to the formula (6)

$\ln [-\ln (1-X(T))]=\ln K(T)-m \ln \beta$

Another method was developed by Liu et al. [44, 47]. For a given conversion degree obtained with the cooling rate of $\beta$ and temperature $T$ the following Eqs. (7-9) are true:

$\ln \beta=\ln F(T)-\alpha \ln t$

$F(T)=[K(T) / k]^{1 / m}$

$\alpha=\frac{n}{m}$

where $F(T)$ is the cooling rate needed at a unit crystallization time when the measured system amounts to the certain degree of crystallinity and $\alpha$ is the ratio of the Avrami exponent to the Ozawa exponent for the chosen conversion degree. 


\section{Isothermal crystallization}

Crystallization of PLA and PLA-based composites was also studied in isothermal conditions using differential scanning calorimetry. The DSC measurement were conducted in the following way: samples were prepared as in the case of nonisothermal tests. They were heated from $20^{\circ} \mathrm{C}$ to $210^{\circ} \mathrm{C}$ at a rate of $30^{\circ} \mathrm{C} / \mathrm{min}$ and held in this temperature for $5 \mathrm{~min}$ to erase the thermal history of the material. Then, they were cooled at a rate of $30^{\circ} \mathrm{C} / \mathrm{min}$ to the chosen crystallization temperature and held for 1 hour. Finally, the samples were heated once again to $210^{\circ} \mathrm{C}$ at a rate of $10^{\circ} \mathrm{C} / \mathrm{min}$ to evaluate the melting behavior.

The crystallization kinetics was evaluated according to Avrami method, using formulas (2) and (3). The values of $k$ and $n$ were determined by plotting $\log [-\ln (1-X(t))]$ as a function of $\log (t)$ and fitting a linear function. The experimental points in the conversion degree of $3 \%$ to $50 \%$ were used in order to exclude the secondary crystallization phenomenon, which is not described by the Avrami formula [45]. The Avrami exponent was found as the slope of the line and $\log k$ is the intercept.

Crystallization of PLA and PLA-based composites was supplemented by isothermal crystallization studies conducted by polarized light optical microscopy (POM). Application of POM allows to observe the crystallites of the samples subjected to crystallization at different temperature values $\left(100-140^{\circ} \mathrm{C}\right)$. First, $10 \mu \mathrm{m}$ thick slices were cut out of the injection molded samples using a Leica RM2265 microtome. The samples were placed on glass slides on a Linkam TMHS 600 hot plate. The heating/cooling program was the same as in the case of DSC measurements, but after crystallization the samples were cooled to room temperature at a rate of $30^{\circ} \mathrm{C} / \mathrm{min}$. The crystalline structures were observed using a Nikon Eclipse E400 microscope with a magnification of 80x, equipped with an Opta Tech digital camera. To evaluate both the spherulitic structure and filler dispersion in the samples with different $\mathrm{LC}$ grades, the isothermal crystallization at $130^{\circ} \mathrm{C}$ was performed. Based on the preliminary studies it was decided, that this temperature results in structure with relatively big crystallites, which are easy to observe.

\section{Results and discussion}

\section{Non-isothermal crystallization}

The DSC curves obtained with the heating/cooling rate of $10^{\circ} \mathrm{C} / \mathrm{min}$ are presented in Fig. 1 . The values of crystallinity degree calculate according to formula (1) based on the second heating cycle are presented in the graph. For the pure PLA sample, typical thermograms were obtained. The inflection visible at the heating curve around $63^{\circ} \mathrm{C}$ can be attributed to relaxation of the PLA amorphous domains (glass transition). Then, the exothermic peak around $95^{\circ} \mathrm{C}$ indicates presence of so-called cold crystallization, that is crystallization of a material during heating. This behavior is typical for the aliphatic polyesters such as PLA, which due to the build of the macromolecules does not crystallize easily $[15,48,49]$. It means that the cooling rate of $10^{\circ} \mathrm{C} /$ min are high enough to quench the molten polymer [50]. Melting of PLA takes place around $160-180^{\circ} \mathrm{C}$, as indicated by an endothermic peak. A small exothermic peak visible on the heating curve just before melting can be attributed to additional crystallization [51]. Another explanation is
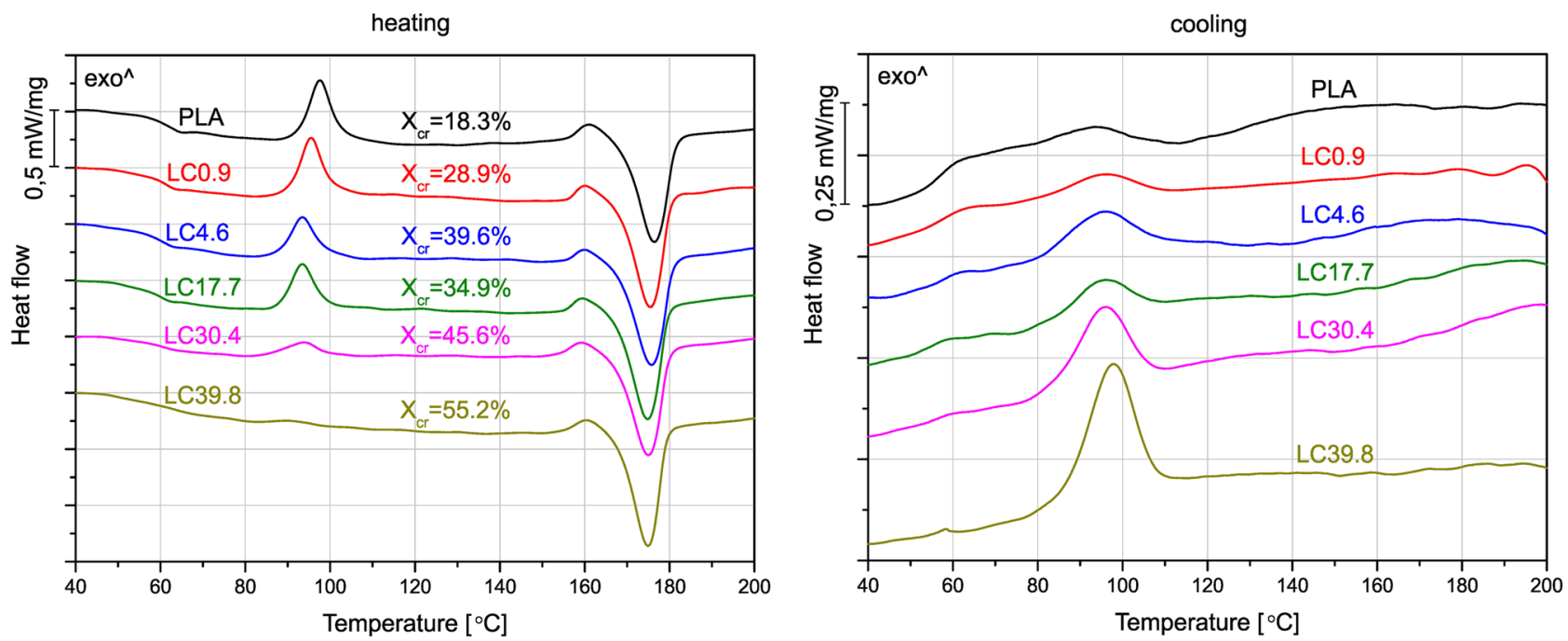

Fig. 1 DSC curves obtained during heating (left) and cooling (right) of the samples with a rate of $10^{\circ} \mathrm{C} / \mathrm{min}$ 

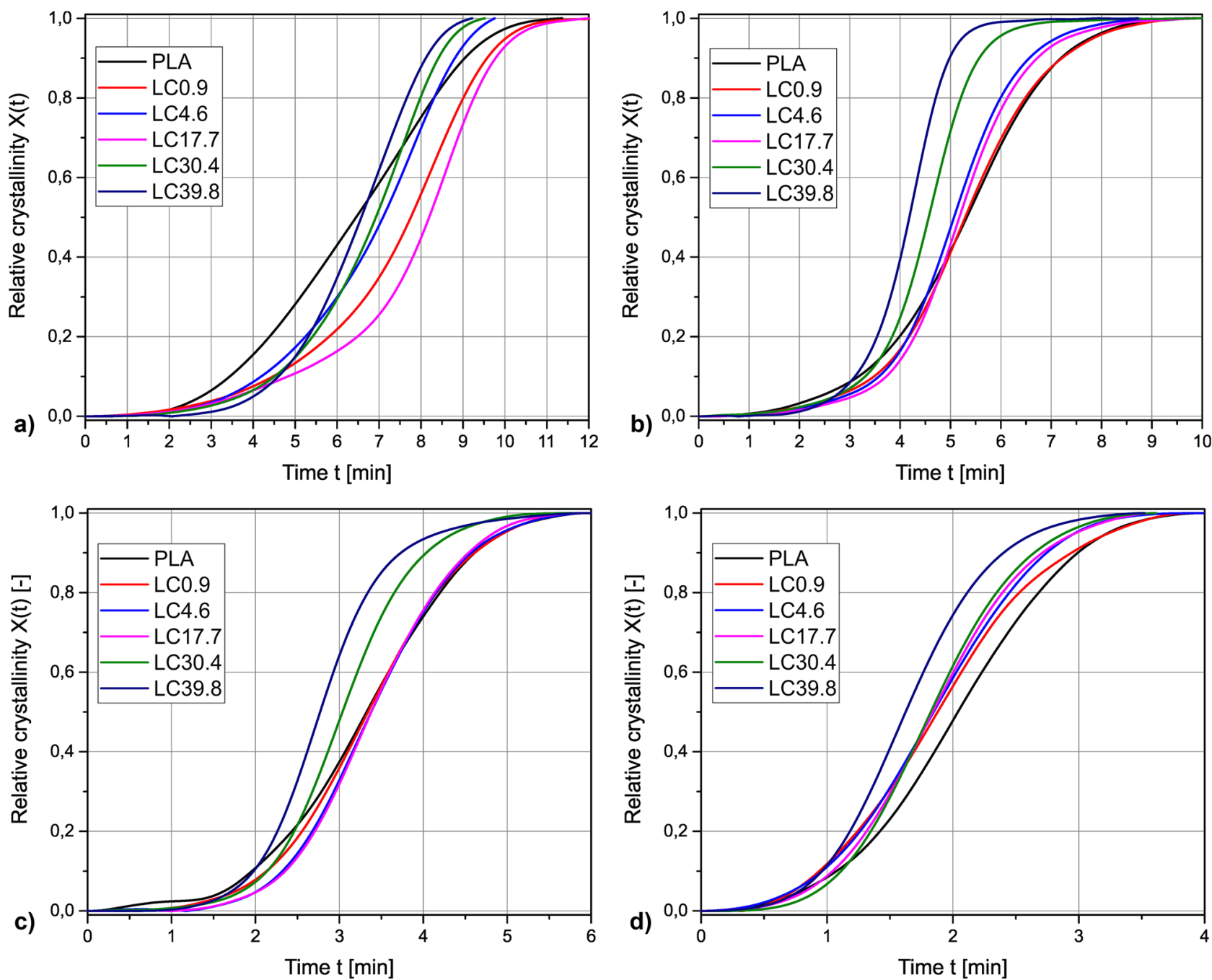

Fig. 2 Relative crystallinity $X(t)$ in function of crystallization time t obtained for PLA and its composites during cooling at a rate of: a) $2.5^{\circ} \mathrm{C} /$ min, b) $5^{\circ} \mathrm{C} / \mathrm{min}$, c) $7.5^{\circ} \mathrm{C} / \mathrm{min}$ and d) $10^{\circ} \mathrm{C} / \mathrm{min}$

disorder-to-order ( $\alpha^{\prime}$ to $\alpha$ ) phase transition, as it was in the case of PLLA by Zhang et al. [52]. When analyzing the cooling curve of pure PLA, only a broad and not distinctive crystallization peak around $95^{\circ} \mathrm{C}$ can be seen. This result confirms that the crystallization rate of PLA is too slow to obtain semicrystalline structure during cooling at a rate of $10^{\circ} \mathrm{C} / \mathrm{min}$.

Addition of linseed cake with different oil content changes the melting and crystallization behavior of PLA, even though the temperatures of cold crystallization, melting and melt crystallization ( $T c c, T m$ and $T c$, respectively) change insignificantly. However, it can be observed that the cold crystallization peak decreases along with increasing oil content in the filler, whereas the melt crystallization exotherm grows. In the case of the composite containing the highest amount of oil, that is LC39.8, the cold crystallization does not exist. These changes are also reflected by the values of the degree of crystallinity, which increases from $18.3 \%$ for PLA to $55.2 \%$ for the composite sample with the highest oil content. It can be presumed, that the crystallization rate is high enough, so the polymeric composite is not quenched during cooling with $10^{\circ} \mathrm{C} / \mathrm{min}$ rate. This phenomenon can also be explained by changes of the nucleation of crystallites. Based on the obtained data it can be hypothesized that in the case of the oil-rich composites a higher number of active nucleation centers can be formed during cooling and then, during the subsequent heating it is rather growth of spherulites that takes place instead of its nucleation. This change of the phenomena taking place in the polymer results in a different shape of melt and cold crystallization peaks. This result suggests that presence of linseed oil modifies the crystallization behavior of PLA and it is consistent with our previous studies [53], but an in-depth analysis of the kinetics of this process is needed. 
Table 2 The Avrami exponent and crystallization rate values modified according to the Jeziorny's method for the studied samples

\begin{tabular}{|c|c|c|c|c|}
\hline Sample & $\begin{array}{l}\text { Cooling rate } \\
{\left[{ }^{\circ} \mathrm{C} / \mathrm{min}\right]}\end{array}$ & $n_{J}$ & $k_{J}\left[\min ^{-n-}\right]$ & $\mathrm{R}^{2}$ \\
\hline \multirow[t]{4}{*}{ PLA } & 2.5 & 3.23 & 0.082 & 0.9996 \\
\hline & 5 & 2.72 & 0.343 & 0.9952 \\
\hline & 7.5 & 3.65 & 0.533 & 0.9987 \\
\hline & 10 & 2.48 & 0.786 & 0.9993 \\
\hline \multirow[t]{4}{*}{ LC0.9 } & 2.5 & 2.60 & 0.086 & 0.9980 \\
\hline & 5 & 3.13 & 0.295 & 0.9909 \\
\hline & 7.5 & 3.84 & 0.504 & 0.9984 \\
\hline & 10 & 2.86 & 0.812 & 0.9990 \\
\hline \multirow[t]{4}{*}{ LC4.6 } & 2.5 & 3.30 & 0.061 & 1.0000 \\
\hline & 5 & 3.49 & 0.265 & 0.9842 \\
\hline & 7.5 & 5.21 & 0.413 & 0.9999 \\
\hline & 10 & 2.57 & 0.808 & 0.9991 \\
\hline \multirow[t]{4}{*}{ LC17.7 } & 2.5 & 2.45 & 0.087 & 0.9996 \\
\hline & 5 & 3.75 & 0.240 & 0.9806 \\
\hline & 7.5 & 4.96 & 0.422 & 0.9984 \\
\hline & 10 & 3.15 & 0.788 & 0.9997 \\
\hline \multirow[t]{4}{*}{ LC30.4 } & 2.5 & 3.62 & 0.046 & 0.9969 \\
\hline & 5 & 3.64 & 0.270 & 0.9869 \\
\hline & 7.5 & 4.82 & 0.456 & 0.9981 \\
\hline & 10 & 3.88 & 0.766 & 0.9999 \\
\hline \multirow[t]{4}{*}{ LC39.8 } & 2.5 & 5.22 & 0.016 & 0.9999 \\
\hline & 5 & 5.23 & 0.196 & 0.9990 \\
\hline & 7.5 & 5.21 & 0.462 & 0.9990 \\
\hline & 10 & 3.47 & 0.811 & 0.9997 \\
\hline
\end{tabular}

The plots of relative crystallinity $X(t)$ vs time obtained during cooling with different rates for all the studied materials are presented in Fig. 2. All the samples present an S-shaped curve, which is typical for crystallization of polymers [26]. In the case of both the pure PLA and its composites, the increase of cooling rate results in the shorter time needed to complete the crystallization, but the degree of the changes depends on the linseed cake grade. During the experiment conducted with the lowest cooling rate, pure PLA sample presents a visibly different curve shape in comparison with the composites. In its case the crystallization begins earlier but due to less steep slope of the curve, the samples LC30.4 and LC39.8 achieve the $100 \%$ of relative crystallinity at a shorter time. The increase of heating rate results in a more similar run of the conversion degree curves for the pure polymer and its composites. During the test performed with heating rates of $5-10^{\circ} \mathrm{C} / \mathrm{min}$, the samples with the highest oil content complete the process at the shortest time. The composites containing up to $17.7 \mathrm{wt} \%$ of linseed oil crystallize slower and its crystallization time is comparable to the one of the pure PLA. Even though the LC30.4 and LC39.8 complete crystallization at a shortest time, no clear relationship of the linseed oil content and the run of conversion degree curves was found.

As it can be seen, the influence of oil content in the filler and the crystallization of PLA-based composites is complex. Therefore, the crystallization rate $k$ was calculated using the method proposed by Jeziorny. The values of the Avrami exponent and crystallization rate calculated according to the Jeziorny's method are collected in Table 2.

As it is indicated by $\mathrm{R}^{2}>0.98$, the experimental points are well fitted to the model. The $n_{J}$ values indicate the nucleation and crystallite growth mechanism during the non-isothermal crystallization. For the pure PLA, the exponent values obtained for different cooling rates are in the range of 2.48-3.65. The $n_{J}$ values around 2.61-3.23 are commonly obtained for this polymer $[20,26,54]$ and they indicate spherulitic growth from the crystallization seeds initiated at the beginning of the process and plate-like growth from the nuclei initiated in further stages of the process [44]. The lowest value denoted for the highest heating rate may indicate two-dimensional growth of nuclei [44]. It can be concluded that fast cooling of PLA changes the mechanism of crystallization. In the case of the crystallization rate $k_{J}$ of the neat polymer a visible relationship of this parameter and cooling rate can be observed. The fastest the cooling, the higher crystallization rate, which is also a typical behavior [54].

The Avrami exponent for the composite samples is the range of $2.45-5.52$, but its values change with both the cooling rate and the linseed oil content. The lowest $n_{J}$ values were obtained for $\beta$ of $2.5^{\circ} \mathrm{C} / \mathrm{min}$ and they increased with the cooling rate up to $7.5^{\circ} \mathrm{C} / \mathrm{min}$. Afterwards, a decrease of the Avrami exponent was observed for all the samples. It can be stated that the nucleation and growth of the crystallites is influenced by the cooling rate and consequently, supercooling. When $\beta$ is either too low or too high, the spherulites cannot fully develop [26]. For the majority of the studied composites, the highest $n_{J}$ values around 5 were obtained with $7.5^{\circ} \mathrm{C} / \mathrm{min}$ cooling rate, indicating three dimensional solid-sheaf growth with athermal nucleation [55]. Interestingly, the Avrami exponents of the LC-filled samples containing lower amounts of the oil change in the function of heating rate to a greater extent than the oil-rich ones. For example, in the case of the LC17.7 composite, the $n_{J}$ values increase from 2.45 to 4.96 and for the LC30.4 one - from 3.62 to 4.82 . Therefore, it may be concluded that addition of the oil-rich waste filler makes the crystallization behavior of PLA more uniform and less dependent on the cooling conditions. What is more, the Avrami exponent values of specimen with the highest linseed oil content are notably high (up to 5.52) even for the lowest cooling rate. Addition of linseed cake to PLA changes the nucleation behavior from two-dimensional to three dimensional, but the most notable results can be achieved for the samples with the highest oil 

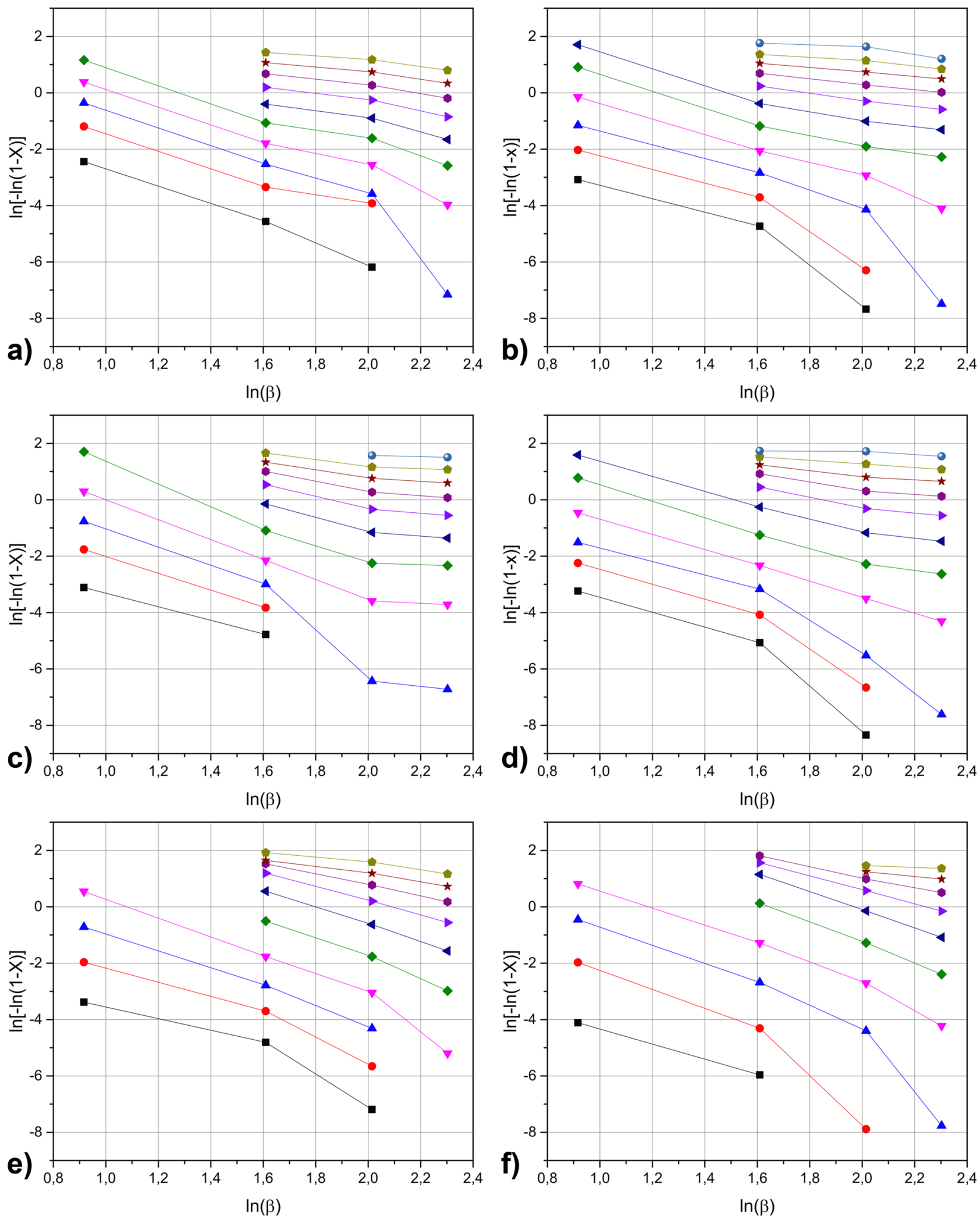

Fig. 3 Ozawa plots for a) PLA, b) LC0.9, c) LC4.6, d) LC17.7, e) LC30.4 and f) LC39.8 samples. Separate curves were drawn for each temperature 
Table 3 The values of $\alpha$ and $F(T)$ parameters for different conversion degrees

\begin{tabular}{|c|c|c|c|c|}
\hline Sample & $\begin{array}{l}\text { Conversion } \\
\text { degree }\end{array}$ & $\alpha$ & $F(T)$ & $\mathrm{R}^{2}$ \\
\hline \multirow[t]{4}{*}{ PLA } & 0.2 & 0.67 & 12.95 & 0.9849 \\
\hline & 0.4 & 0.71 & 15.82 & 0.9870 \\
\hline & 0.6 & 0.74 & 18.53 & 0.9892 \\
\hline & 0.8 & 0.78 & 21.99 & 0.9900 \\
\hline \multirow[t]{4}{*}{ LC0.9 } & 0.2 & 0.56 & 11.69 & 0.9584 \\
\hline & 0.4 & 0.64 & 14.42 & 0.9712 \\
\hline & 0.6 & 0.69 & 16.94 & 0.9766 \\
\hline & 0.8 & 0.73 & 20.23 & 0.9832 \\
\hline \multirow[t]{4}{*}{ LC4.6 } & 0.2 & 0.56 & 11.83 & 0.9403 \\
\hline & 0.4 & 0.64 & 14.35 & 0.9541 \\
\hline & 0.6 & 0.70 & 16.98 & 0.9574 \\
\hline & 0.8 & 0.76 & 20.39 & 0.9599 \\
\hline \multirow[t]{4}{*}{ LC17.7 } & 0.2 & 0.57 & 12.10 & 0.9495 \\
\hline & 0.4 & 0.63 & 14.34 & 0.9589 \\
\hline & 0.6 & 0.68 & 16.58 & 0.9619 \\
\hline & 0.8 & 0.72 & 19.43 & 0.9634 \\
\hline \multirow[t]{4}{*}{ LC30.4 } & 0.2 & 0.65 & 12.55 & 0.9661 \\
\hline & 0.4 & 0.72 & 14.93 & 0.9730 \\
\hline & 0.6 & 0.78 & 17.56 & 0.9751 \\
\hline & 0.8 & 0.86 & 21.49 & 0.9737 \\
\hline \multirow[t]{4}{*}{ LC39.8 } & 0.2 & 0.62 & 11.48 & 0.9595 \\
\hline & 0.4 & 0.69 & 13.57 & 0.9687 \\
\hline & 0.6 & 0.76 & 15.91 & 0.9722 \\
\hline & 0.8 & 0.85 & 19.54 & 0.9682 \\
\hline
\end{tabular}

content. The relative independence on the heating rate and Avrami exponent values presented by the LC39.8 sample suggests that presence of linseed oil facilitates the growth of polylactide crystallites. Similar results were obtained in the case of PLA plasticized with PEG, where the plasticizer promoted the crystal growth [56]. Therefore, it may be concluded that the linseed oil act as a plasticizer in PLA matrix.

Similarly to the pure PLA, the crystallization rate of the composites increases with the cooling rate. The highest crystallization rate of 0.812 was obtained for the LC0.9 sample cooled at a rate of $10^{\circ} \mathrm{C} / \mathrm{min}$, but no direct relationship of $k_{J}$ and oil content in the linseed cake was found. The crystallization rate values calculated for the different samples cooled with the same heating rate are comparable and the changes can be explained by random factors, such as the signal processing by the measuring system and its resolution, as well as the shape and size of samples. This result can be counterintuitive, as the oil-rich samples were shown to complete the crystallization earlier than their counterparts (see Fig. 2). Apparently, the observed changes in non-isothermal crystallization time result from the changes of nucleation and crystallite growth behavior rather than the increase of crystallization rate. When the crystallites growth in 3 dimensions, a shorter time is needed to complete this process in comparison to the 2-D layer-by-layer growth, even when the $k_{J}$ values are comparable. It can be also assumed that due to differences in growth of the nuclei, the influence of oil content on crystallization rate is more pronounced in the further stages of the process, as the analysis was performed for the conversion degree in the range of $3-20 \%$.

The $\ln [-\ln (1-X(t))]$ vs. $\ln \beta$ plots shown in Fig. 3 were prepared in order to evaluate the non-isothermal crystallization of the PLA-based samples according to the method proposed by Ozawa [46]. The crystallization rate $k(T)$ as well as the exponent $m$ describing the crystallites' growth should be obtained from the intercept and slope of the lines fitted to the experimental points. However, as it can be observed in Fig. 3, the experimental points do not fit to the Ozawa's model. The changes in the lines' slopes indicates that the value of $m$ is not constant during the process and secondary crystallization takes place [44]. The changes of crystallization rate in temperature could also explain the incoherence of the crystallization time and $k_{J}$ comparison. Similar results were obtained in the case of non-isothermal melt crystallization PLA-based composites modified with carbon black [20] or polylactide filled with egg shells and plasticized with poly(ethylene glycol) [26].

In similar cases the method created by Mo et al. was successfully used [44, 47]. The values of $\alpha$ and $F(T)$ parameters for the pure PLA and the composites obtained for the conversion degrees of $0.2,0.4$., 0.6 and 0.8 are collected in Table 3. The $\mathrm{R}^{2}$ values, also presented in Table 3 are mostly above 0.95 , which indicates that the studied materials fit the model. Nevertheless, the fitting is not perfect which presumably results from the presence of multiple phases in the materials.

The $\alpha$ parameter is the ratio of Avrami exponent $n$ to the Ozawa exponent $m$. For the pure PLA it is in the range of $0.67-0.78$ and it increases in the function of conversion degree. The $\alpha$ values of the composites follow a similar pattern. For the samples LC0.9, LC4.6 and LC17.7 they are lower than for the pure resin, from 0.56 at $20 \%$ relative crystallinity to 0.76 at $80 \%$. A visible increase of $\alpha$ values can be observed in the case of the composites with the highest oil content - the ratio of Avrami and Ozawa exponent is as high as 0.85 at a conversion degree of $80 \%$.

The $F(T)$ is a parameter which indicates the cooling rate which is needed to obtain a chosen degree of crystallinity [26]. It is connected to the polymer's crystallization rate and its higher value signalizes slower crystallization [17]. As it can be seen in Table 3, $F(T)$ generally 
Fig. 4 Determination of equilibrium melting temperature for chosen samples

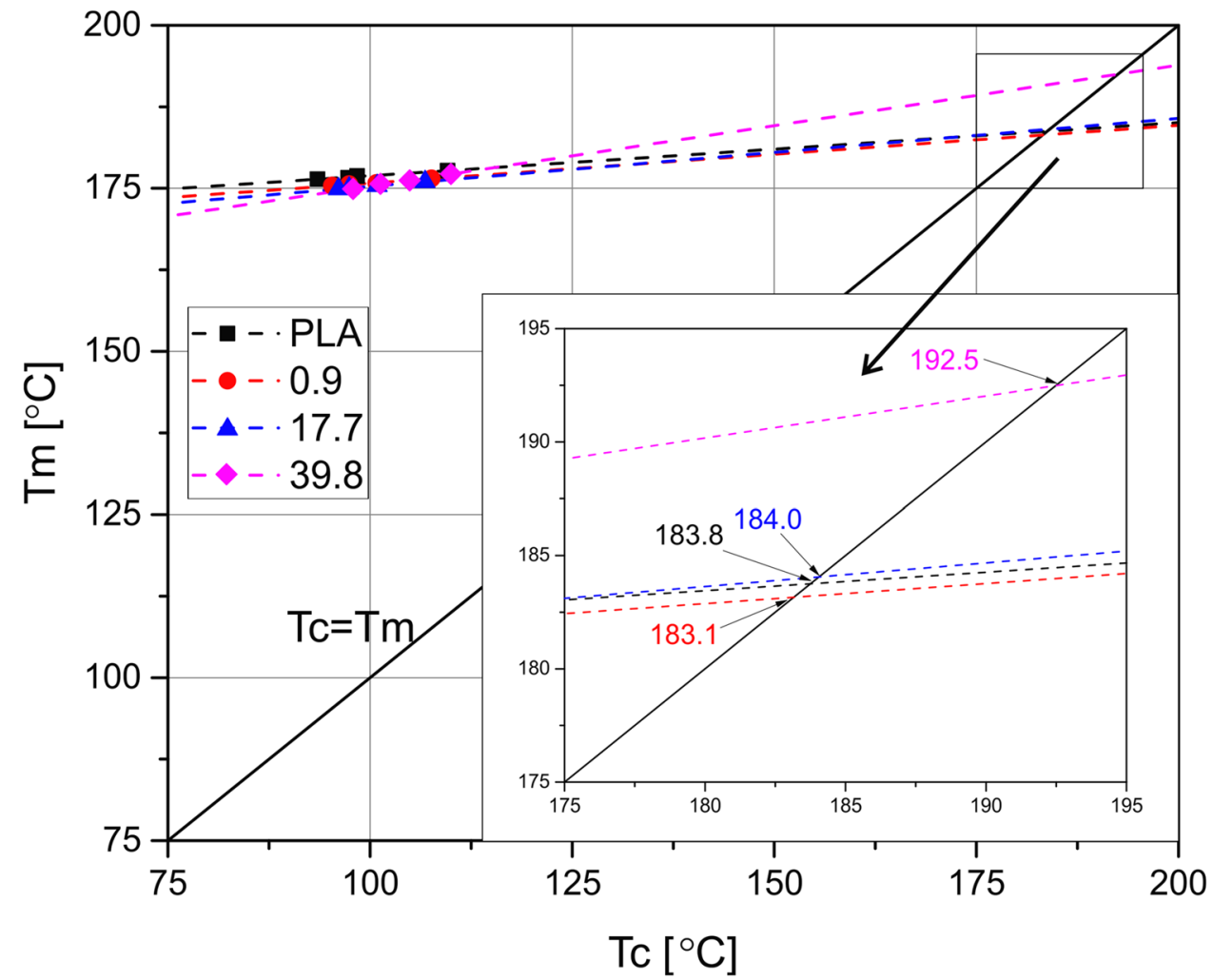

increases with the relative crystallinity, which means that at the higher conversion degree a higher cooling rate should be applied [17]. Pure PLA can be characterized with $F(T)$ in the range of 12.95-21.99 in the crystallinity range of $20-80 \%$, which is rather low for this polymer but not atypical [20]. Even though the lowest $F(T)$ values of 11.48-19.54 are achieved by the LC39.8, no clear correlation of the linseed oil content and this parameter can be seen. Nevertheless, all the composite samples reveal lower $F(T)$ values than pure PLA, which indicates that the process of crystallization is faster for the LC-filled materials. This result is in line with the simple comparison of the crystallization curves presented in Fig. 2.

Based on the experimental data, equilibrium melting temperature values $\mathrm{Tm}^{0}$ of the chosen samples were obtained from the crossover point of $T m=T c$ line and the extrapolation of $T m$ as a function of $T c$ [57], as it is shown in Fig. 4. The equilibrium melting temperature of pure PLA is $183.8^{\circ} \mathrm{C}$, which is in the range typically obtained for this polymer $[20,23]$. The composites with the lower oil content present $\mathrm{Tm}^{0}$ values almost identical to the one of the neat polymer. Interestingly, the equilibrium melting temperature of the LC39.8 sample is about $10^{\circ} \mathrm{C}$ higher than for the remaining samples. This behavior can be explained by a more perfect structure of the crystallites in the composite modified by linseed oil $[23,57]$.

\section{Isothermal crystallization}

The microstructures of the isothermally crystallized LC39.8 composite and the pure PLA observed using the optical microscope in the polarized light are presented in Fig. 5. As it can be observed, crystalline structure was obtained for both materials crystallized in all the chosen temperatures. The lowest $T c$ results in exceptionally fine structure with individual crystallites measuring below $10 \mu \mathrm{m}$. The rate of nucleation is higher than the rate of spherulites' growth, therefore the crystallites are densely packed, small and irregular. This behavior can be attributed to the regime III of crystallization, according to Hoffman theory [58]. When crystallization takes place in $100^{\circ} \mathrm{C}$ or $110^{\circ} \mathrm{C}$, no observable difference between the pure PLA and the linseed cake-filled composite can be spotted. The increase of Tc to $120^{\circ} \mathrm{C}$ causes a notable increase of spherulites, which is especially prominent for the pure PLA. When the crystallization temperature of $130^{\circ} \mathrm{C}$ is applied, the polylactide crystallites achieve a size of almost $100 \mu \mathrm{m}$. Their shape is almost spherical, however, the growth of one crystallite is limited by the others. It can be stated that in $130^{\circ} \mathrm{C}$ the crystallization regime II by Hoffman [58] takes place. In the case of LC-filled sample, the structure is comparable to the one of pure polymer, but the crystallites are smaller. The major difference between the PLA and LC39.8 can be 
Fig. 5 Microstructures of PLA and LC39.8 samples crystallized isothermally in different temperatures
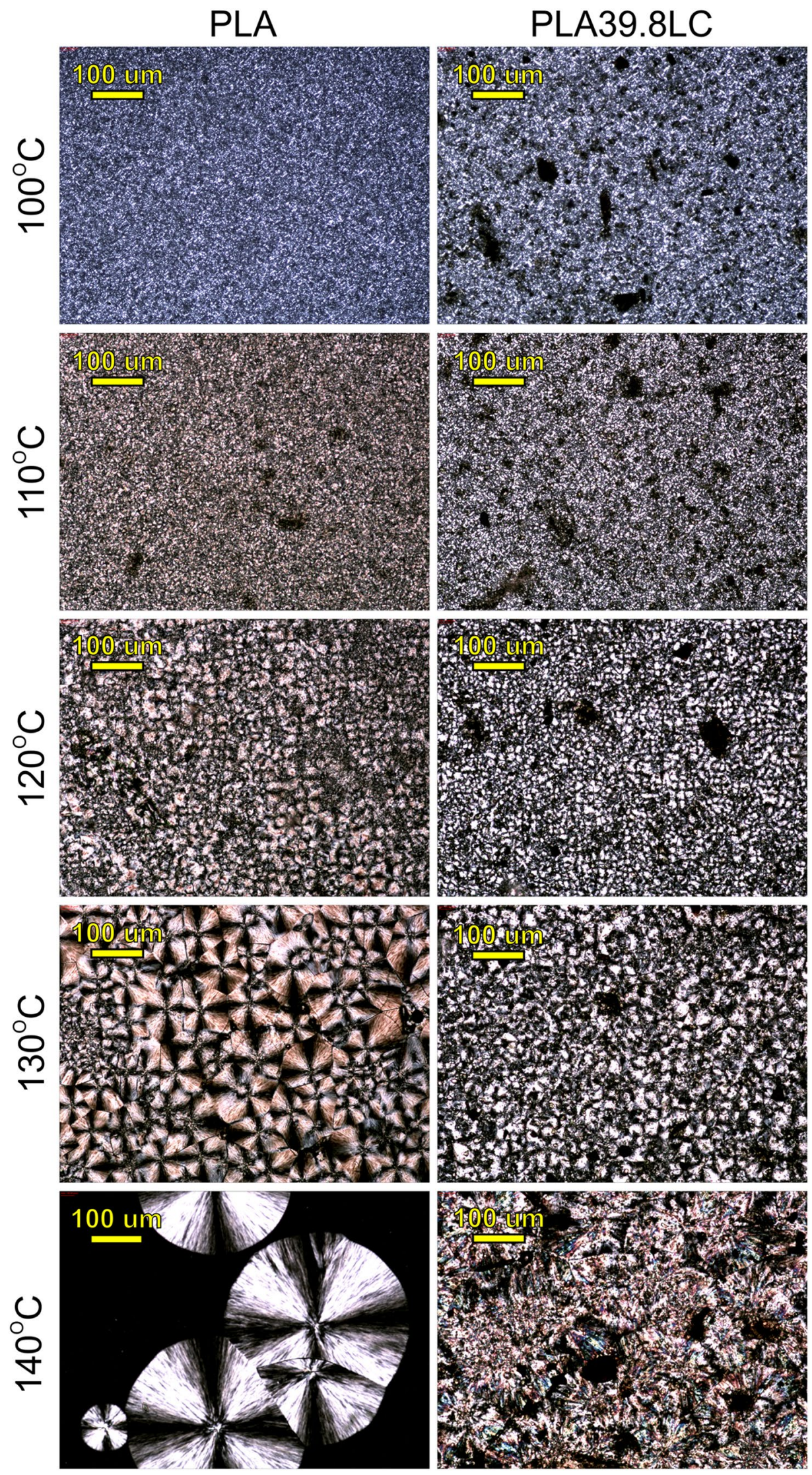
Fig. 6 Microstructures of PLA and different LC-filled composites crystallized isothermally at $130^{\circ} \mathrm{C}$. Filler particles are colored in red
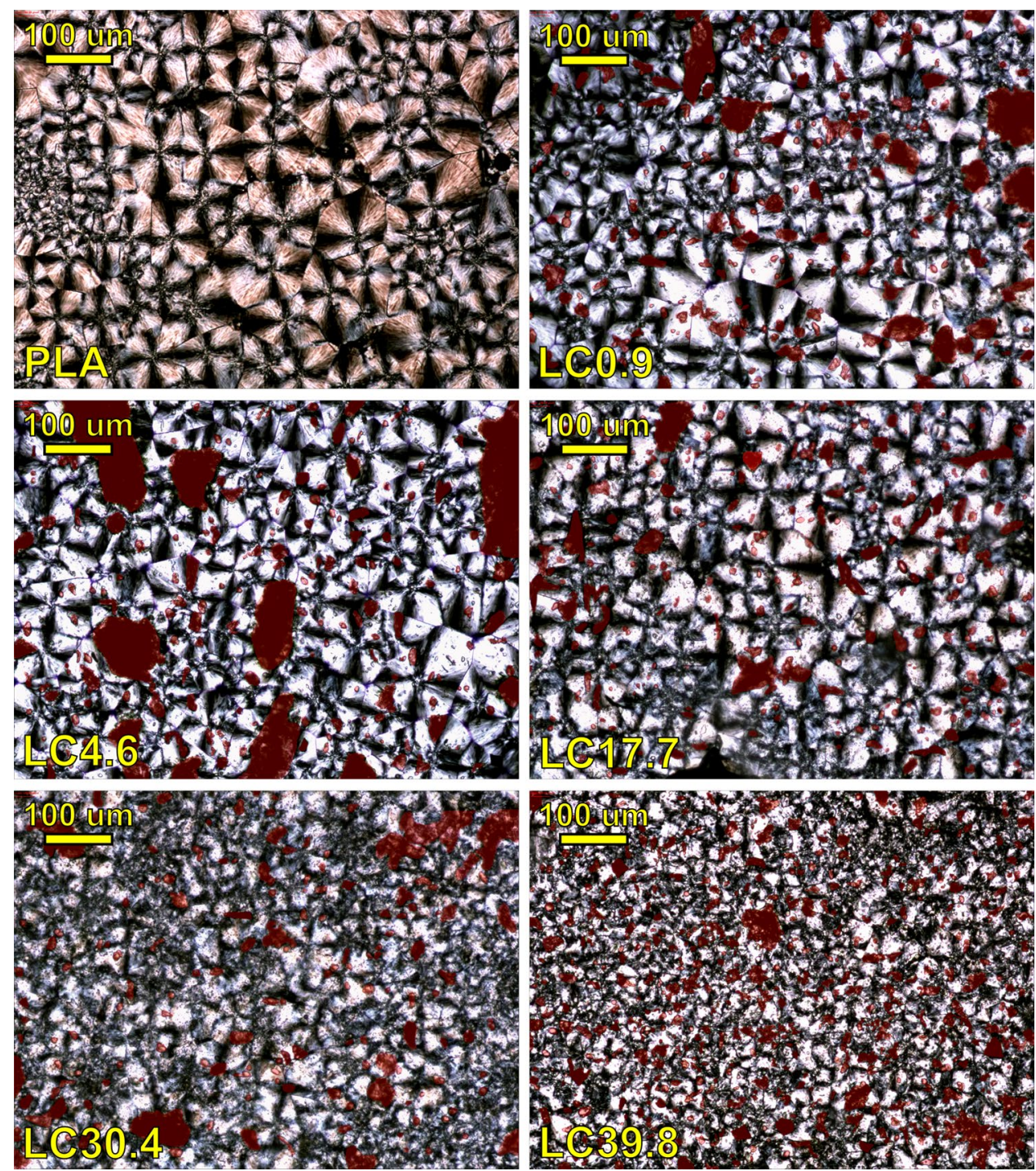

noticed for the samples crystallized in $140^{\circ} \mathrm{C}$. In the case of pure polyester, individual spherulites with the diameter about $100-400 \mu \mathrm{m}$ can be seen, but most of the sample stays amorphous. Apparently, the supercooling is too low to cause the crystallization of the whole volume of the polymer. The rate of nucleation is visibly lower than the rate of the crystallite growth, which can be ascribed to the crystallization regime I by Hoffman [58]. The composite sample shows a completely different behavior. The whole observable sample is in a crystalline form, the only dark spots are the lignocellulosic filler particles. Large crystallites differ in shape and optical properties from the spherulites observed for pure PLA sample. The differences in the microstructure's appearance can result from lamellar twisting during crystallization [59] due to unbalanced stress on the lamellar growth front [60]. It can be presumed that the linseed oil can be absorbed on crystal boundaries and therefore increase the surface stress at lamellas, similarly to the non-crystallizing components of polymeric blends which show this behavior [59]. Interestingly, the lignocellulosic particles do not act as centers of crystallites' growth. As addition of LC did not significantly change the melting point of the polymer, the supercooling for the LC39.8 particle was roughly the same as for the pure polymer, yet it did allow the crystallization. Therefore, it can be concluded, that presence of linseed cake increases the crystallite growth rate in PLA. It also needs to be noticed that LC particles are not the crystallization seeds, so linseed cake is not a nucleating agent for PLA, even though it influences its crystallization.

To further analyze the influence of the filler and its dispersion on the crystalline structure of the composites, isothermally crystallized composite samples with different LC grades are shown in Fig. 6. First, the filler particles (marked in red) are dispersed in the whole volume 

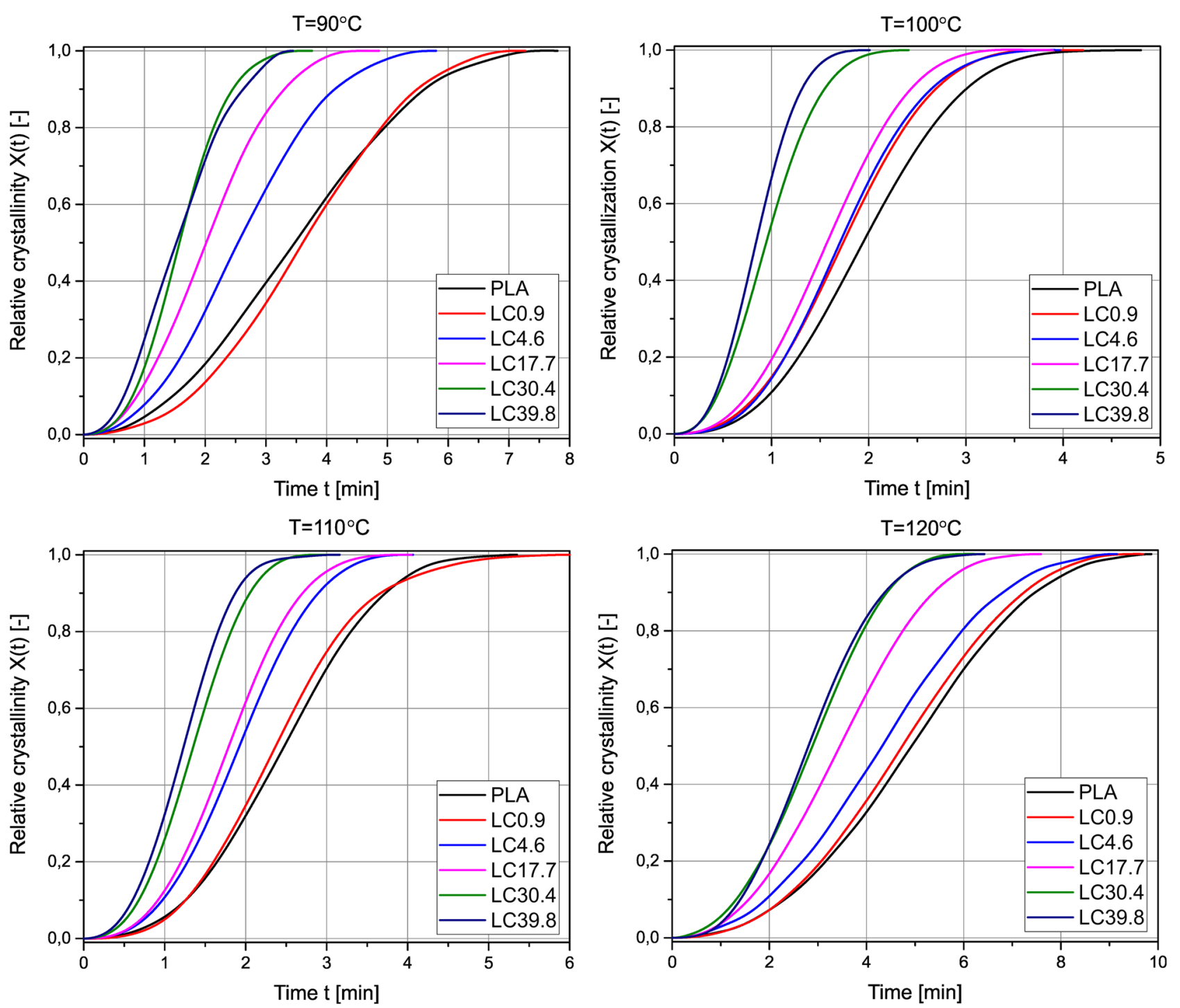

Fig. 7 Relative crystallinity $X(t)$ in function of crystallization time t obtained for PLA and its composites during isothermal crystallization at temperature of $90,110,110$ or $120^{\circ} \mathrm{C}$

of the composite, but their size differs among the studied samples. The composites such as LC0.9 and LC 4.6, containing the lowest oil content, can be characterized with the largest particle size and distribution. Presumably, the defatted LC particles, containing more lignin and holocellulose are more resistant to shearing forces during the melt mixing of the composite using the twin-screw extruder and injection molding of the samples, whereas the oil-rich linseed cake is softer and easier to pulverize. It needs to be noticed that the used filler particles, especially in the case of the higher oil content, do not create aggregates, which confirms its good compatibility with PLA.
Spherulites are present in microstructures of all the studied materials. The size of the crystallites in the LC0.9 and LC4.6 composites is similar to the one present in the unfilled PLA. The higher the oil content, the smaller spherulites can be observed, which indicates that the oil is the main factor influencing the crystallization of PLA. Moreover, the fact that both the particle and spherulite size decrease for the oil-rich samples, it can be presumed that the finer particles have larger contact area with the polymeric matrix, so their interaction are more intense and the influence on the crystallization is more notable. However, the placement of the crystallites is not connected to the particles - they do not serve as centers of crystallization. It can be concluded that 

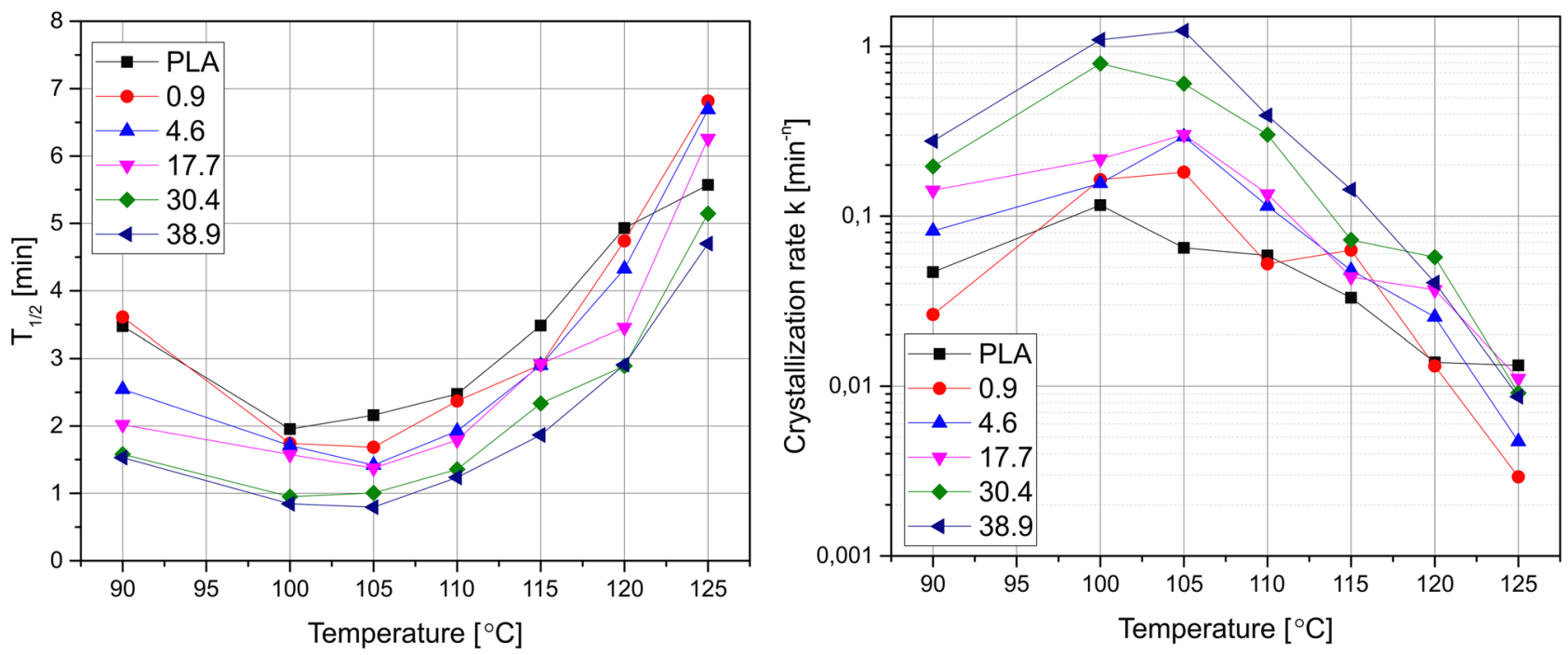

Fig. 8 Crystallization half time (left) and crystallization half time (right) as functions of temperature for the pure PLA and its composites

oil present in the linseed cake influences both the filler distribution and spherulitic structure of PLA-based composites, but the LC particles do not serve as seeds of crystallization.

The run of crystallization curves obtained during the isothermal experiment are shown in Fig. 7 and the plots of crystallization rate $k$ and crystallization half time $t_{1 / 2}$ (i.e. the time needed to obtain $50 \%$ relative crystallinity) in function of temperature are presented in Fig. 8. It can be observed that the $t_{1 / 2}$ values determined for all the studied materials present a similar relationship with the temperature - the minimum of crystallization half time (the optimum crystallization temperature Topt) takes place about $100-105^{\circ} \mathrm{C}$. There is a notable difference of $t_{1 / 2}$ values between the PLA and its composites in the whole temperature range. The neat polymer has the crystallization half time of $2.16-5.57 \mathrm{~min}$. The samples LC0.9, LC4.6 and LC17.7 present similar but smaller $t_{1 / 2}$ values. The only exception is the result obtained during isothermal crystallization at $125^{\circ} \mathrm{C}$, when the pure PLA achieved 50\% relative crystallinity sooner than the composites with $0.9-17.7 \%$ oil in the filler. The composites with the highest oil content have the shortest crystallization half time - for LC 39.8 it is in the range of $0.80-4.70 \mathrm{~min}$. The values of crystallization rate obtained during isothermal crystallization are presented in Fig. 8 as a function of temperature. Logarithmic y-axis was chosen to better present the differences between the $k$ value obtained for the studies samples, as the differences between them are several orders of magnitude high. The isothermal crystallization rate is notably influenced by
Table 4 The Avrami exponent $\mathrm{n}$ values for the studied samples crystallized at different temperatures

\begin{tabular}{lllllllll}
\hline \multicolumn{7}{l}{ Crystallization temperature $\left[{ }^{\circ} \mathrm{C}\right]$} \\
\hline Sample & Result & 90 & 100 & 105 & 110 & 115 & 120 & 125 \\
PLA & $n$ & 2.16 & 2.69 & 3.08 & 2.71 & 2.42 & 2.43 & 2.27 \\
& $\mathrm{R}^{2}$ & 0.999 & 1 & 0.999 & 0.999 & 0.999 & 0.999 & 0.998 \\
LC0.9 & $n$ & 2.52 & 2.56 & 2.53 & 3.03 & 2.20 & 2.54 & 2.81 \\
& $\mathrm{R}^{2}$ & 0.998 & 0.999 & 0.999 & 0.999 & 0.998 & 0.999 & 0.994 \\
LC4.6 & $n$ & 2.44 & 2.79 & 2.64 & 2.73 & 2.50 & 2.22 & 2.62 \\
& $\mathrm{R}^{2}$ & 0.998 & 1 & 0.999 & 0.999 & 0.999 & 0.998 & 0.999 \\
LC17.7 & $n$ & 2.24 & 2.54 & 2.58 & 2.78 & 2.53 & 2.35 & 2.24 \\
& $\mathrm{R}^{2}$ & 1 & 1 & 0.999 & 0.999 & 0.998 & 0.999 & 0.999 \\
LC30.4 & $n$ & 2.73 & 2.45 & 2.68 & 2.87 & 2.64 & 2.30 & 2.64 \\
& $\mathrm{R}^{2}$ & 0.999 & 1 & 1 & 0.999 & 0.999 & 0.999 & 0.999 \\
LC39.8 & $n$ & 2.31 & 2.55 & 2.57 & 2.57 & 2.48 & 2.77 & 2.83 \\
& $\mathrm{R}^{2}$ & 0.999 & 1 & 0.999 & 0.999 & 0.999 & 0.999 & 1 \\
\hline
\end{tabular}


Table 5 Comparison of the kinetic parameters of melt crystallization of PLA-based materials determined in the present study and described in the literature

\begin{tabular}{|c|c|c|c|c|c|}
\hline Conditions & & Material & $n$ & $k$ & Ref \\
\hline \multirow[t]{13}{*}{ Non-isothermal melt crystallization } & \multirow{13}{*}{$\begin{array}{l}\text { Cooling rate of } \\
5^{\circ} \mathrm{C} / \mathrm{min}\end{array}$} & PLA & 2.72 & 0.323 & \multirow[t]{2}{*}{ Present study } \\
\hline & & LC39.8 & 5.23 & 0.196 & \\
\hline & & PLA & 4.77 & 0.384 & \multirow[t]{4}{*}{ [19] } \\
\hline & & $\mathrm{PLA}+2.5 \mathrm{wt} \% \mathrm{SiO} 2$ & 6.15 & 0.427 & \\
\hline & & PLA + $2.5 \mathrm{wt} \% \mathrm{MMT}$ & 4.52 & 0.302 & \\
\hline & & PLA + $2.5 \mathrm{wt} \% \mathrm{MWCNT}$ & $2.63 / 7.69$ & $0.220 / 0.287$ & \\
\hline & & PLA & - & - & \multirow[t]{3}{*}{ [54] } \\
\hline & & $\mathrm{PLA}+1 \% \mathrm{PTMC}$ & 2.29 & 0.980 & \\
\hline & & PLA + 1\%PPETC & 2.15 & 1.050 & \\
\hline & & PLA & 2.8 & 0.020 & \multirow[t]{2}{*}[17]{} \\
\hline & & PLA + 15wt $\%$ TPP & 2.9 & 0.006 & \\
\hline & & PLA & 3.94 & 0.578 & \multirow[t]{2}{*}[25]{} \\
\hline & & PLA $+7 \%$ jojoba oil & 3.08 & 0.679 & \\
\hline \multirow[t]{19}{*}{ Isothermal melt crystallization } & \multirow[t]{9}{*}{$T c=100^{\circ} \mathrm{C}$} & PLA & 2.69 & 0.116 & \multirow[t]{2}{*}{ Present study } \\
\hline & & LC39.8 & 2.55 & 1.092 & \\
\hline & & PLA & 3.30 & $2.19 \cdot 10^{-4}$ & \multirow[t]{2}{*}[21]{} \\
\hline & & $\mathrm{PLA}+0.2 \mathrm{wt} \% \mathrm{CNT}$ & 3.00 & 0.017 & \\
\hline & & PLA & 3.06 & $8.709 \cdot 10^{-14}$ & \multirow[t]{2}{*}{ [16] } \\
\hline & & PLA $+5 w t \%$ talc & 2.31 & 0.025 & \\
\hline & & PLA & 2.23 & 0.005 & \multirow[t]{3}{*}[51]{} \\
\hline & & PLA $+10 \mathrm{wt} \%$ starch & 2.36 & 0.083 & \\
\hline & & PLA + $1 w t \%$ talc & 1.69 & 2.800 & \\
\hline & \multirow[t]{2}{*}{$T c=104^{\circ} \mathrm{C}$} & PLA & 2.50 & 0.003 & \multirow[t]{2}{*}[61]{} \\
\hline & & PLA + 1wt $\%$ Graphene nanosheets & 2.52 & 0.008 & \\
\hline & \multirow[t]{2}{*}{$T c=114^{\circ} \mathrm{C}$} & PLA & 2.26 & $2.69 \cdot 10^{-4}$ & \multirow[t]{2}{*}[23]{} \\
\hline & & PLA + 10wt \% Triphenyl Phosphate & 2.24 & 0.002 & \\
\hline & \multirow[t]{4}{*}{$T c=120^{\circ} \mathrm{C}$} & PLA & 2.60 & $1.25 \cdot 10^{-5}$ & \multirow[t]{4}{*}[26]{} \\
\hline & & PLA + 20wt $\%$ PEG & 2.30 & 0.001 & \\
\hline & & PLA $+20 w t \%$ eggshells & 2.60 & 0.031 & \\
\hline & & PLA + 20wt $\%$ PEG + 20\% eggshells & 2.20 & 0,251 & \\
\hline & \multirow[t]{2}{*}{$T c=140^{\circ} \mathrm{C}$} & PLA & 2.40 & $7.94 \bullet 10^{-11}$ & \multirow[t]{2}{*}[15]{} \\
\hline & & PLA $+1 \%$ Lak & 2.80 & 0.127 & \\
\hline
\end{tabular}

both the temperature and the sample's composition. The highest $k$ values were denoted in the case of crystallization temperature around Topt, for all the composites. As it reveals from Fig. 8, the linseed cake-modified samples with the highest oil content present the highest crystallization rate. For the LC39.8 specimen the maximum values exceed $1 \mathrm{~min}^{-n}$. The difference between pure PLA and its composites is especially visible for crystallization temperatures below Topt, where the crystal growth determines the overall crystallization rate [24] due to the increased mobility of polylactide macromolecules in the presence of the natural oil, especially in the lower range of the temperatures, i.e. around Topt and below.
The values of the Avrami exponent $n$ obtained during isothermal crystallization of PLA and its composites are collected in Table 4. For pure PLA, the $n$ values are in the range of 2.16-3.08 and the highest value was recorded for crystallization at Topt. The composite samples have the Avrami exponent values in a similar range as the pure PLA. No clear relationship of the $n$ value and the temperature or linseed cake type was seen. As the $n$ values around 2 indicate two dimensional crystallite growth on a lamellar structure and the Avrami exponent close to 4 suggest three dimensional heterogeneous crystal growth from an instantaneous nucleation [16, 21], it can be concluded that a mixed nucleation and crystallite growth takes place in the case of PLA and its composites. 


\section{Conclusion}

In influence of linseed oil grades with different oil content on crystallization of PLA was studied. A comparison of the crystallization parameters determined in the present study and described in the literature is presented in Table 5. A clear influence of oil content in the filler on non-isothermal as well as isothermal crystallization was observed, but the exact behavior depended on the measurement conditions. It was observed that crystallization of oil-rich composites is faster in both isothermal and non-isothermal conditions, but the mechanism of the changes is different. When the process is conducted at constant temperature (constant supercooling), the addition of oil-rich linseed cake notably increases the crystallization rate of PLA, but the mechanism of nucleation and growth of crystallites does not change in comparison with pure polymer. The difference between the linseed cake-filled and neat polylactide is especially prominent in the lower range of temperatures, when the crystallization rate is mostly dependent on the crystallites growth. In non-isothermal conditions the crystallization rate of the composite samples and the unmodified polylactide is comparable but the nucleation of crystallites is faster and their growth changes from two- to three dimensional. Based on the obtained data it can be concluded that LC particles do not act as nucleation seeds by themselves, but natural oil promotes the movement of macromolecules, which results in easier self-nucleation and subsequent growth of crystallites.

In the industrial practice non-isothermal crystallization usually takes place, e.g. during cooling injection molded polymer in the mold. It can be predicted that addition of LC to PLA can result creation of more perfect crystalline structure in a shorter time, and consequently - a faster production of good quality parts.

Acknowledgements Presented work has been financed by the Ministry of Science \& Higher Education in Poland in 2020 year under Project No 0513/SBAD/4608.

\section{Compliance with ethical standard}

Conflict of interests The authors declare no conflict of interests.

Open Access This article is licensed under a Creative Commons Attribution 4.0 International License, which permits use, sharing, adaptation, distribution and reproduction in any medium or format, as long as you give appropriate credit to the original author(s) and the source, provide a link to the Creative Commons licence, and indicate if changes were made. The images or other third party material in this article are included in the article's Creative Commons licence, unless indicated otherwise in a credit line to the material. If material is not included in the article's Creative Commons licence and your intended use is not permitted by statutory regulation or exceeds the permitted use, you will need to obtain permission directly from the copyright holder. To view a copy of this licence, visit http://creativecommons.org/licenses/by/4.0/.

\section{References}

1. Castro-Aguirre E, Iñiguez-Franco F, Samsudin $\mathrm{H}$ et al (2016) Poly(lactic acid) - Mass production, processing, industrial applications, and end of life. Adv Drug Deliv Rev 107:333-366. https: //doi.org/10.1016/J.ADDR.2016.03.010

2. Auras R, Harte B, Selke S (2004) An overview of polylactides as packaging materials. Macromol Biosci 4:835-864. https://doi. org/10.1002/mabi.200400043

3. Jin FL, Hu RR, Park SJ (2019) Improvement of thermal behaviors of biodegradable poly(lactic acid) polymer: A review. Compos B Eng 164:287-296. https://doi.org/10.1016/j.compositesb. 2018.10.078

4. McKeown P, Jones MD (2020) The Chemical Recycling of PLA: A Review. Sustainable Chemistry 1:1-22. https://doi.org/10.3390/ suschem 1010001

5. Moraczewski K, Malinowski R, Sikorska W et al (2019) Composting of Polylactide Containing Natural Anti-Aging Compounds of Plant Origin. Polymers 11:1582. https://doi.org/10.3390/polym11101582

6. Fukushima K, Abbate C, Tabuani D et al (2009) Biodegradation of poly(lactic acid) and its nanocomposites. Polym Degrad Stab 94:1646-1655. https://doi.org/10.1016/J.POLYMDEGRADSTAB. 2009.07.001

7. Sikorska W, Musioł M, Rydz J, et al (2019) Kompostowanie przemysłowe jako metoda zagospodarowania odpadów $\mathrm{z}$ materiałów poliestrowych otrzymywanych z surowców odnawialnych. Polimery 64:818-827. https://doi.org/10.14314/polimery. 2019.11.11

8. Hossain KMZ, Parsons AJ, Rudd CD et al (2014) Mechanical, crystallisation and moisture absorption properties of melt drawn polylactic acid fibres. Eur Polymer J 53:270-281. https://doi. org/10.1016/j.eurpolymj.2014.02.001

9. Andrzejewski J, Cheng J, Anstey A et al (2020) Development of Toughened Blends of Poly(lactic acid) and Poly(butylene adipateco -terephthalate) for 3D Printing Applications: Compatibilization Methods and Material Performance Evaluation. ACS Sustainable Chem Eng 8:6576-6589. https://doi.org/10.1021/acssuschemeng. $9 \mathrm{~b} 04925$

10. Benwood C, Anstey A, Andrzejewski J et al (2018) Improving the Impact Strength and Heat Resistance of 3D Printed Models: Structure, Property, and Processing Correlationships during Fused Deposition Modeling (FDM) of Poly(Lactic Acid). ACS Omega 3:4400-4411. https://doi.org/10.1021/acsomega.8b00129

11. Carrasco F, Pagès P, Gámez-Pérez J et al (2010) Processing of poly(lactic acid): Characterization of chemical structure, thermal stability and mechanical properties. Polym Degrad Stab 95:116125. https://doi.org/10.1016/j.polymdegradstab.2009.11.045

12. Nagarajan V, Zhang K, Misra M, Mohanty AK (2015) Overcoming the fundamental challenges in improving the impact strength and crystallinity of PLA biocomposites: Influence of nucleating agent and mold temperature. ACS Appl Mater Interfaces 7:1120311214. https://doi.org/10.1021/acsami.5b01145

13. dos Santos Silva ID, Schäfer H, Jaques NG et al (2020) An investigation of PLA/Babassu cold crystallization kinetics. J Therm Anal Calorim 141:1389-1397. https://doi.org/10.1007/s10973019-09062-2

14. Liao R, Yang B, Yu W, Zhou C (2007) Isothermal cold crystallization kinetics of polylactide/nucleating agents. J Appl Polym Sci 104:310-317. https://doi.org/10.1002/app.25733

15. Nagarajan V, Mohanty AK, Misra M (2016) Crystallization behavior and morphology of polylactic acid (PLA) with aromatic sulfonate derivative. J Appl Polym Sci 133:43673. https://doi. org/10.1002/app.43673 
16. Battegazzore D, Bocchini S, Frache A (2011) Crystallization kinetics of poly(lactic acid)-talc composites. Express Polymer Letters 5:849-858. https://doi.org/10.3144/expresspolymlett.2011.84

17. Xiao H, Yang L, Ren X et al (2010) Kinetics and crystal structure of poly(lactic acid) crystallized nonisothermally: effect of plasticizer and nucleating agent. Polym Polym Compos 31:2057-2068. https://doi.org/10.1002/pc.21004

18. Antoniadis G, Paraskevopoulos KM, Vassiliou AA et al (2011) Nonisothermal melt-crystallization kinetics for in situ prepared poly(ethylene terephthalate)/monmorilonite (PET/OMMT). Thermochim Acta 521:161-169. https://doi.org/10.1016/j. tca.2011.04.019

19. Papageorgiou GZ, Achilias DS, Nanaki S et al (2010) PLA nanocomposites: Effect of filler type on non-isothermal crystallization. Thermochim Acta 511:129-139. https://doi. org/10.1016/j.tca.2010.08.004

20. Su Z, Guo W, Liu Y et al (2009) Non-isothermal crystallization kinetics of poly (lactic acid)/modified carbon black composite. Polym Bull 62:629-642. https://doi.org/10.1007/s00289009-0047-x

21. Park SH, Lee SG, Kim SH (2013) Isothermal crystallization behavior and mechanical properties of polylactide/carbon nanotube nanocomposites. Compos A Appl Sci Manuf 46:11-18. https://doi.org/10.1016/j.compositesa.2012.10.011

22. Yang B, Wang D, Chen F et al (2019) Melting and Crystallization Behaviors of Poly(Lactic Acid) Modified with Graphene Acting as a Nucleating Agent. J Macromol Sci Part B Phys 58:290-304. https://doi.org/10.1080/00222348.2018.1564222

23. Xiao H, Lu W, Yeh J-T (2009) Effect of Plasticizer on the Crystallization Behavior of Poly(lactic acid). J Appl Polym Sci 113:112-121. https://doi.org/10.1002/app.29955

24. Li H, Huneault MA (2007) Effect of nucleation and plasticization on the crystallization of poly(lactic acid). Polymer 48:6855-6866. https://doi.org/10.1016/j.polymer.2007.09.020

25. Saad GR, Elsawy MA, Aziz MSA (2017) Nonisothermal crystallization behavior and molecular dynamics of poly(lactic acid) plasticized with jojoba oil. J Therm Anal Calorim 128:211-223. https://doi.org/10.1007/s10973-016-5910-z

26. Li Y, Han C, Yu Y et al (2018) Crystallization behaviors of poly(lactic acid) composites fabricated using functionalized eggshell powder and poly(ethylene glycol). Thermochim Acta 663:67-76. https://doi.org/10.1016/j.tca.2018.03.011

27. Barczewski M, Mysiukiewicz O, Matykiewicz D et al (2020) Development of polylactide composites with improved thermomechanical properties by simultaneous use of basalt powder and a nucleating agent. Polym Compos 41:2947-2957.https://doi. org/10.1002/pc.25589

28. Orue A, Eceiza A, Arbelaiz A (2018) Preparation and characterization of poly(lactic acid) plasticized with vegetable oils and reinforced with sisal fibers. Ind Crops Prod 112:170-180. https: //doi.org/10.1016/J.INDCROP.2017.11.011

29. Chieng BW, Ibrahim NA, Then YY, Loo YY (2014) Epoxidized vegetable oils plasticized poly(lactic acid) biocomposites: Mechanical, thermal and morphology properties. Molecules 19:16024-16038. https://doi.org/10.3390/molecules 191016024

30. Xu Y-Q, Qu J-P (2009) Mechanical and rheological properties of expoxidized soybean oil plasticized poly(lactic acid). J Appl Phys 112:3185-3191. https://doi.org/10.1002/app

31. Ferri JM, Garcia-Garcia D, Sánchez-Nacher L et al (2016) The effect of maleinized linseed oil (MLO) on mechanical performance of poly(lactic acid)-thermoplastic starch (PLA-TPS) blends. Carbohyd Polym 147:60-68. https://doi.org/10.1016/J. CARBPOL.2016.03.082

32. Battegazzore D, Bocchini S, Alongi J, Frache A (2014) Plasticizers, antioxidants and reinforcement fillers from hazelnut skin and cocoa by-products: Extraction and use in PLA and pp. Polym Degrad Stab 108:297-306. https://doi.org/10.1016/j. polymdegradstab.2014.03.003

33. Bajpai PK, Singh I, Madaan J (2014) Development and characterization of PLA-based green composites: A review. J Thermoplast Compos Mater 27:52-81. https://doi.org/10.1177/0892705712439571

34. Rytlewski P, Stepczynska M, Moraczewski K, et al (2018) Mechanical properties and biodegradability of flax fiber-reinforced composite of polylactide and polycaprolactone. Polimery 63:603-610. https://doi.org/10.14314/polimery.2018.9.4

35. Sałasinska K, Ryszkowska J (2013) Composites of polylactic acid reinforced with plant fillers obtained from farm and food industry. Przemysl Chemiczny 92:2027-2031.

36. Barczewski M, Matykiewicz D, Krygier A et al (2018) Characterization of poly(lactic acid) biocomposites filled with chestnut shell waste. J Mater Cycles Waste Manage 20:914-924. https:// doi.org/10.1007/s10163-017-0658-5

37. Zuk M, Richter D, Matuła J, Szopa J (2015) Linseed, the multipurpose plant. Ind Crops Prod 75:165-177. https://doi.org/10.1016/j. indcrop.2015.05.005

38. Mysiukiewicz O, Barczewski M, Skórczewska K et al (2019) Accelerated Weathering of Polylactide-Based Composites Filled with Linseed Cake: The Influence of Time and Oil Content within the Filler. Polymers 11:1495. https://doi.org/10.3390/POLYM11091495

39. Mysiukiewicz O, Barczewski M (2019) Utilization of linseed cake as a postagricultural functional filler for poly(lactic acid) green composites. J Appl Polym Sci 136:47152. https://doi.org/10.1002/ app.47152

40. Barczewski M, Mysiukiewicz O, Szulc J, Kloziński A (2019) Poly(lactic acid) green composites filled with linseed cake as an agricultural waste filler. Influence of oil content within the filler on the rheological behavior. J Appl Polym Sci 136:47651. https: //doi.org/10.1002/app.47651

41. Najafi N, Heuzey MC, Carreau PJ, Wood-Adams PM (2012) Control of thermal degradation of polylactide (PLA)-clay nanocomposites using chain extenders. Polym Degrad Stab 97:554-565. https://doi.org/10.1016/J.POLYMDEGRADSTAB.2012.01.016

42. Fischer EW, Sterzel HJ, Wegner G (1973) Investigation of the structure of solution grown crystals of lactide copolymers by means of chemical reactions. Colloid Polym Sci 251:980-990

43. Jeziorny A (1978) Parameters characterizing kinetics of nonisothermal crystallization of poly(ethylene-terephthalate) determined by DSC. Polymer 19:1142-1144

44. Wu D, Wu L, Wu L et al (2007) Nonisothermal cold crystallization behavior and kinetics of polylactide/clay nanocomposites. J Polym Sci, Part B: Polym Phys 45:1100-1113. https://doi. org/10.1002/polb.21154

45. Lorenzo AT, Arnal ML, Albuerne J, Müller AJ (2007) DSC isothermal polymer crystallization kinetics measurements and the use of the Avrami equation to fit the data: Guidelines to avoid common problems. Polym Testing 26:222-231. https://doi. org/10.1016/j.polymertesting.2006.10.005

46. Ozawa T (1971) Kinetics of non-isothermal. Polymer 12:150-158

47. Liu T, Mo Z, Wang S, Zhang H (1997) Isothermal melt and cold crystallization kinetics of poly(aryl ether ether ketone ketone) (PEEKK). Eur Polymer J 33:1405-1414. https://doi.org/10.1016/ S0014-3057(97)00016-5

48. Schmidt SC, Hillmyer MA (2001) Polylactide Stereocomplex Crystallites as Nucleating Agents for Isotactic Polylactide. J Polym Sci, Part B: Polym Phys 39:300-313. https://doi.org/10.1002/10990488(20010201)39:3\%3c300::AID-POLB1002\%3e3.0.CO;2-M

49. Gilbert M, Hybart FJ (1974) Effect of chemical structure on crystallization rates and melting of polymers: 2. Aliphatic polyesters Polymer 15:407-412. https://doi.org/10.1016/00323861(74)90102-5

50. Shieh Y-T, Liu G-L (2007) Temperature-modulated differential scanning calorimetry studies on the origin of double melting peaks 
in isothermally melt-crystallized poly(L-lactic acid). J Polym Sci, Part B: Polym Phys 45:466-474. https://doi.org/10.1002/polb

51. Ke T, Sun X (2003) Melting behavior and crystallization kinetics of starch and poly(lactic acid) composites. J Appl Polym Sci 89:1203-1210. https://doi.org/10.1002/app.12162

52. Zhang J, Tashiro K, Tsuji H, Domb AJ (2008) Disorder-to-order phase transition and multiple melting behavior of poly(L-lactide) investigated by simultaneous measurements of WAXD and DSC. Macromolecules 41:1352-1357. https://doi.org/10.1021/ma0706071

53. Mysiukiewicz O, Barczewski M, Skórczewska K et al (2019) Accelerated Weathering of Polylactide-Based Composites Filled with Linseed Cake: The Influence of Time and Oil Content within the Filler. Polymers 11:1495. https://doi.org/10.3390/POLYM11091495

54. Gui Z, Lu C, Cheng S (2013) Comparison of the effects of commercial nucleation agents on the crystallization and melting behaviour of polylactide. Polym Testing 32:15-21. https://doi. org/10.1016/j.polymertesting.2012.08.011

55. Qiu Z, Mo Z, Yu Y et al (2000) Nonisothermal melt and cold crystallization kinetics of poly(aryl ether ketone ether ketone ketone). J Appl Polym Sci 77:2865-2871. https://doi.org/10.1002/10974628(20000923)77:13\%3c2865::AID-APP7\%3e3.0.CO;2-2

56. Chen L, Dou Q (2020) Influence of the combination of nucleating agent and plasticizer on the non-isothermal crystallization kinetics and activation energies of poly(lactic acid). J Therm Anal Calorim 139:1069-1090. https://doi.org/10.1007/s10973-019-08507-y

57. Wu TM, Chen EC (2006) Crystallization behavior of poly $(\varepsilon-$ caprolactone)/multiwalled carbon nanotube composites. J Polym
Sci, Part B: Polym Phys 44:598-606. https://doi.org/10.1002/ polb. 20722

58. Patki R, Mezghani K, Phillips PJ (2007) Crystallization kinetics of polymers. In: Phisical Properties of Polymers Handbook. pp 282-347

59. Li J, Li Y, Zhou J et al (2011) Increasing lamellar twisting frequency with poly(lactic acid) segments incorporation in poly(trimethylene terephthalate) ring-banded spherulites. Macromolecules 44:2918-2925. https://doi.org/10.1021/ma1025434

60. Lohmeijer PJA, Goossens JGP, Peters GWM (2017) Quiescent crystallization of poly(lactic acid) studied by optical microscopy and light-scattering techniques. J Appl Polym Sci 134:2-10. https: //doi.org/10.1002/app.44566

61. Wu D, Cheng Y, Feng S et al (2013) Crystallization behavior of polylactide/graphene composites. Ind Eng Chem Res 52:67316739. https://doi.org/10.1021/ie4004199

Publisher's Note Springer Nature remains neutral with regard to jurisdictional claims in published maps and institutional affiliations. 